\title{
Pengembangan Simulator Engine Trainer Integrated Active Wiring Diagram untuk Meningkatkan Efektifitas Pembelajaran Pada Mata Kuliah Listrik dan Elektronika Otomotif
}

\author{
Rifdarmon ${ }^{{ }^{*}}$ \\ ${ }^{1}$ Jurusan Teknik Otomotif, Fakultas Teknik, Universitas Negeri Padang \\ *Corresponding author, e-mail: rifdarmon@ft.unp.ac.id
}

\begin{abstract}
Abstrak - Berdasarkan observasi awal, hasil belajar mahasiswa Jurusan Teknik Otomotif pada mata kuliah Listrik dan Elektronika Otomotif belum memuaskan kemungkinan oleh keterbatasan media pembelajaran yang ada. Penelitian ini bertujuan untuk merancang simulator Engine trainer integratedwiring diagram aktif untuk dipakai sebagai media pembelajaran pada mata kuliah Listrik dan Elektronika otomotif. Maksud penelitian ini untuk mengukur kevalidan, kepraktisan, dan keefektifan simulator yang akan dikembangkan agar layak digunakan di saat praktikum, bentuk penelitian yang digunakan ini adalah Research and Development $(R \& D)$ dengan prosedur pengembangan model 4-D. Penelitian ini terdiri dari empat tahap, yaitu: define, design, develop, disseminate. Subjek yang digunakan adalah mahasiswa jurusan teknik Otomotif yang sedang mengambil mata kuliah Listrik dan Elektronika Otomotif. Teknis analisis data yang dipakai adalah teknis analisis data deskriptif yaitu mendeskripsikan kevalidan, kepraktisan dan keefektifan Simulator Engine Trainer integrated wiring diagram aktif. Praktikalitas simulator berdasarkan respon dosen dinyatakan sangat praktis dengan nilai $90,77 \%$ dan $87 \%$ pada respon praktis mahasiswa. Persentase ketuntasan belajar mahasiswa setelah mengikuti pembelajaran dengan menggunakan simulator engine trainer integrated wiring diagram aktif yang dikembangkan sebagai media pembelajaran sebesar $\mathbf{7 6 , 9 7 \%}$. Efektifitas alat dinyatakan efektif dalam meningkatkan hasil belajar mahasiswa. Berdasarkan temuan penelitian yang dilakukan bahwa simulator yang digunaka valid, praktis, dan efektif untuk dimanfaatkan sebagai media pembelajaran pada mata kuliah Listrik dan Eletronika Otomotif.
\end{abstract}

Kata kunci : Simulator, Engine Trainer, validitas, praktikalitas daan efektifitas

Abstract-Based on the beginning, student learning outcomes in the field of engineering and Automotive Electronics has not been satisfactory by the existing learning media. This research is intended to examine the Engine Trainer simulator integratedwiring diagram active to be used as a medium of learning in the subject of Electrical and Electronics electronics. The purpose of this study is to measure the validity, validity and effectiveness of the simulators that will be developed to be easy at the time of the lab, this type of research is Research and Development $(R \& D)$ with 4-D model development procedure. This research consists of four stages, namely: defining, designing, developing, disseminating. The subject is a student majoring in Automotive engineering who is taking courses Electrical and Electronics Automotive. Technical data analysis techniques that are descriptive analysis that is by describing the validity, validity and effectiveness of Engine Trainer Simulator integrated wiring diagram active. Practice simulator based on the lecturer's response is very practical with the value of $90.77 \%$ and $87 \%$ on the students practical response. Percentage mastery of student learning after following learning by using simulator engine trainer integrated wiring diagram that developed as learning media equal to 76,97\%. Effectiveness of effective tools in improving student learning outcomes. Based on the findings of this study it is concluded that the simulator is valid, practical, and effective for use as a medium of learning in Electrical and Automotive Eletechics courses.

Keywords : Simulator, Engine Trainer, validity, practicality and effectiveness

This is an open access article distributed under the Creative Commons 4.0 Attribution License, which permits unrestricted use, distribution, and reproduction in any medium, provided the original work is properly cited. (C2018 by Author and Universitas Negeri Padang 


\section{Pendahuluan}

Pendidikan Nasional bermaksud untuk mengembangkan potensi peserta didik supaya menjadi manusia yang beriman dan bertaqwa terhadap Tuhan Yang Maha Esa, berakhlak mulia, berilmu, pandai, kreatif, mandiri, dan membuati negara yang demokratis serta bertanggung jawab mencerdaskan bangsa. Pendidikan sebagai indikator kemajuan bangsa dipandang sangat penting dalam proses pembangunan. Oleh sebab itu, harus adanya penyempurnaan terus menerus dan berkesinambungan supaya kualitas pendidikan semakin meningkat Sistem pendidikan nasional di Indonesia telah dirumuskan dalam UUD Republik Indonesia nomor 20 Tahun 2003 yaitu Sistem Pendidikan Nasional. Salah satu yang termasuk dalam sistem pendidikan nasional sebagaimana tercantum dalam UU tersebut adalah adanya jalur pendidikan menurut UU RI no.20 Tahun 2003 yaitu: "Pendidikan Nasional berfungsi mengembangkan dan membentuk watak serta peradaban bangsa yang bermartabat dalam rangka mencerdaskan kehidupan bangsa, bertujuan untuk berkembangnya potensi peserta didik agar menjadi manusia yang beriman dan bertakwa kepada Tuhan Yang Maha Esa, berakhlak mulia, sehat, berilmu, cakap, kreatif, mandiri, dan menjadi warga negara yang demokratis dan bertanggung jawab".

Proses pembelajaran yang diterapkan oleh tenaga pengajar harus melihatkan spesifikasi dan karakteristik dari mata kuliah serta perkembangan sehingga dalam proses pembelajaran tercipta suasana kelas yang kondusif dan menarik mahasiswa untuk mengikuti pembelajaran. Dengan bantuan alat peraga akan lebih mudah mamahami konsep / prinsip, pembuatan kerja maupun membuat materi yang abstrak jadi lebih konkret.

Program studi S1 Pendidikan Teknik Otomotif Universitas Negeri Padang sudah berdiri sejak tahun 1992. Salah satu mata kuliah yang ada pada Jurusan Pendidikan Teknologi Otomotif adalah Mata Kuliah Listrik dan Elektronika Otomotif yang merupakan mata kuliah wajib yang harus ditempuh oleh mahasiswa Pendidikan Teknik Otomotif. Tujuan mata kuliah ini adalah mampu memberikan pengetahuan dan keterampilan tentang kelistrikan dan elektronika mobil yang mencakup baterai, sistem starter, sistem penyalaan, sistem pengisian, sistem kontrol dan komputer serta mampu mencari dan mengatasi gangguangangguan dan pada sebuah kendaraan. Di dalam teori pembelajaran, pakar pendidikan gagne, Briggs dan wager menyatakan proses seseorang dapat berpengaruh oleh faktor internal peserta didik itu sendiri dan faktor eksternal, proses belajar terjadi karena sinergi memori singkat dan panjang diaktifkan melalui rangsangan eksternal, yaitu pembelajaran atau lingkungan belajar melalui inderanya, peserta didik dapat menyerap materi.

Berdasarkan observasi dan wawancara dengan dosen yang mengajar mata kuliah Listrik dan Elektronika Otomotif yang telah penulis lakukan sebelumnya, dalam proses pembelajaran materi mengenai pengenalan Listrik dan Elektronika Otomotif, proses pembelajaran dilakukan dengan menggunakan media power point, video dan Engine Trainer serta di pandu buku manual dan modul pembelajaran. Idealnya sebagai seorang mahasiswa Teknik Otomotif harusnya memahami mengenai fenomena - fenomena yang terjadi pada sistem kontrol sensor dan actuator pada sistem kelistrikan dan Sistem Elektronik Otomotif beserta penanganan gangguannya. Pada perkuliahan ini media belum mengintegrasikan antara teori kelistrikan dan praktek kelistrikan otomotif sehingga terjadi discrepancy atau ketidaksesuaian antara hasil perkuliahan yang di dapat mahasiswa dengan sinopsis perkuliahan. Pembelajaran elektronika semakin banyak masuk ke bidang otomotif. Hal ini menuntut kreativitas dalam membuat media pembelajaran seperti pembuatan peraga sensor yang menggunakan pendekatan otomotif [1].

Peneliti memilih menggunakan media Engine TrainerIntegrated Wiring Diagram Aktif pada Mata Kuliah Lisrik dan Elektronika Otomotif karena memiliki kelebihan untuk mendemonstrasikan suatu fenomena yang sulit diamati, bisa menjelaskan yang abstrak serta bisa melaksanakan amanat kurikulum 2013 yang menggunakan metode scientific, maka dari itu penggunaan alat peraga engine trainer yang sudah Integrated dengan wiring diagram aktif pada perkuliahan ini adalah salah satu solusi dalam melakukan pembelajaran aktif dengan metode scientific.

Simulator ini sesuai untuk memecahkan masalahan di atas adalah menggunakan pemodelan sistem aliran kelistrikan otomotif yang di sederhanakan dan menggambarkan hal yang sebenarnya. Simulator suatu pemodelan dari sebuah sistem yang sebenarnya dan apabila di berikan perlakuan akan menimbulkan gejala seperti gejala yang timbul pada kelistrikan mobil sesungguhnya. Alat ini dinamakan Engine TrainerIntegrated Wiring Diagram Aktif karena engine trainer diintegrasikan dengan wiring diagram yang bisa diberi perlakukan sesuai 
keinginan pemakai dan gejala langsung bisa diamati dan bisa terukur dengan alat ukur standar dari sebuah mobil yang menggunakan scantool untuk pendiaknosaan.

Penggunaan Engine TrainerIntegrated Wiring Diagram Aktif sebagai simulator diharapkan mampu meningkatkan efektifitas pembelajaran, motivasi dan rasa ingin tahu mahasiswa mengenai nama komponen, fungsi komponen, letak komponen, cara kerja komponen, cara kerja sistem rangkain kelistrikan, pendiagnosaan (trouble shooting), bisa membuka, menyetel, mengukur, membersihkan serta memasang sistem dan komponen khususnya kelistrikan engine, sehingga meningkatkan hasil belajar.

\section{Studi Pustaka}

Untuk memahami peranan media dalam proses mendapatkan pengetahuan belajar bagi siswa, edgar dale menetapkan dalam bentuk kerucut yang kemudian dinamakan kerucut pengetahuan (cone experience), seperti pada gambar 1

Kerucut pengalaman yang dikemukakakan oleh Edgar Dale memberikan gambaran bahwa pengetahuan belajar yang diperoleh peserta didik dapat juga proses perbuatan atau mengalami sendiri apa yang dipelajari, proses mengamati dan mendengarkan melalui media tertenu dan proses mendengarkan melalui bahasa. Semakin konkret siswa mempelajari bahan pengajaran contohnya melalui pengalaman langsung, maka semakin banyaklah pengetahuan yang diperoleh peserta didik. Sebaliknya, semakin abstrak peserta didik dapat pengetahuan contohnya hanya mengandalkan bahasa verbal, terjadi semakin sedikit pengetahuan yang akan diperoleh siswa.

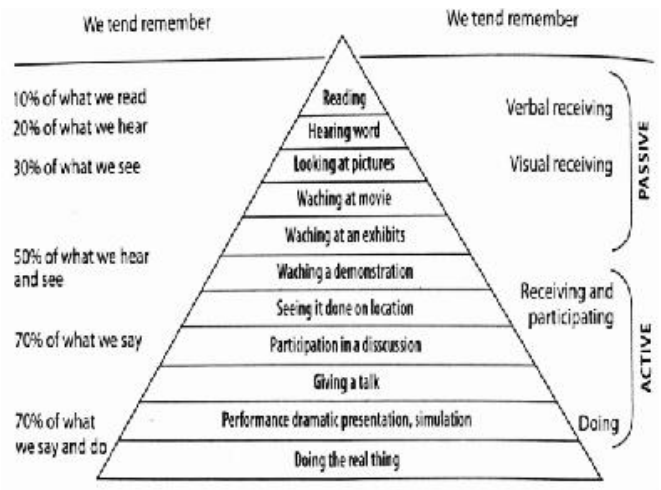

Sumber: Wina Sanjaya (2008) [3]

Gambar 1 Kerucut pengetahuan Edgard Dale
Selanjutnya, uraian setiap pengetahuan belajar seperti yang ada dalam kerucut pengetahuan ini akan dijelaskan di bawah ini:

a. Pengetahuan langsung merupakan pengalaman yang diproleh perseta didik sebagai hasil dari aktivitas sendiri.

b. Pengetahuan tiruan adalah yang diperoleh benda atau terjadi yang dimani pulasi agar mendekati bentuk yang sebenarnya.

c. Pengetahuan melalui drama, yaitu pengetahuan yang didapat dari kondisi dan situasi yang terciptakan melalui drama (peragaan) menggunakan skenario yang ditetapkan dengan tujuan yang hendak dicapai.

d. Pengetahuan melalui demonstrasi adalah suatu penyampaian informasi melalui penampilan.

e. Pengetahuan wisata, yaitu pengetahuan yang diperoleh melalui kunjungan peserta didik ke suatu benda yang ingin dipelajari.

f. Pengetahuan melalui pameran. Pameran adalah bentuk menunjukkan hasil karya

g. Pengetahuan melalui televisi merupakan pengetahuan tidak langsung, karena televisi merupakan perantara.

h. Pengetahuan melalui gambar hidup dan film. Gambar hidup atau film merupakan gambar mati yang diproyeksikan pada layar dengan kecepatan yang terlah ditentukan.

i. Pengetahuan melalui radio, tape recorder dan gambar.

j. Pengetahuan melalui lambang-lambang visual, yaitu grafik, gambar, dan bagan.

k. Pengetahuan melalui lambang verbal, yaitu pengetahuan yang sifatnya lebih abstrak.

Apabila kita perhatikan kerucut pengetahuan yang di kemukakan Edgar Dale, maka dapat kesimpukan bahwa pengetahuan itu dapat diperoleh melalui pengalaman langsung dan pengalaman tidak langsung. Semakin langsung objek yang dipelajari, maka semakin konkret pengetahuan diperoleh semakin tidak langsung pengetahuan itu diperoleh, maka semakin abstrak pengetahuan siswa.

\section{METODE}

Penelitian dan Pengembangan atau Research and Development $(R \& D)$ adalah suatu proses atau langkah-langkah untuk mengembangkan suatu produk baru, atau menyempurnakan produk yang telah ada, yang dapat dipertanggung jawabkan. Produk tersebut tidak selalu benda atau perangkat keras ( hardware), seperti buku, modul alat bantu 
pembelajaran dikelas atau di laboratorium, tapi juga bisa juga perangkat lunak atau software, seperti program komputer untuk pengolahan data, pembelajaran di kelas, perpustakaan atau laboratorium, ataupun model-model pendidikan, pembelajaran, pelatihan, bimbingan, evaluasi, manajemen, dll. Menurut Sugiono (2011: 407) Metode Penelitian dan Pengembangan adalah metode penelitian yang digunakan untuk menghasilkan produk tertentu, dan menguji keefektifan produk tersebut.

Menurut Sukmadinata (2005:164), penelitian dan Pengembangan (Research and Development) adalah suatu proses atau langkah-langkah untuk mengembangkan suatu produk yang telah ada, yang dapat dipertanggungjawabkan. Metode penelitian dan pengembangan (Reseach and Development) juga didefinisikan sebagai penelitian yang secara sengaja, sistematis, bertujuan/diarahkan untuk mencari dan merumuskan, memperbaiki, mengembangkan, menghasilkan, menguji, keefektifan produk, model, metode/strategi/cara, jasa, prosedur tertentu yang lebih unggul, baru, efektif, efisien, produktif , dan bermakna (Putra,2012:6)

Prosedur pengembangan alat Engine Trainer Integrated wiring Diagram yang akan digunakan sebagai Simulator pada mata kuliah Listrik dan Elektronika Otomotif menggunakan model 4-D yang dikemukakan oleh Silvasailam Thiagaraja, Dorothy S.Semmel, Melvyn I.Semmel (1974) yang terdiri dari 4 tahap utama yaitu, Define (pendefinisian), Design (perancangan), Develop (pengembangan) dan Disseminate (Penyebaran).

Model 4-D dipilih dalam penelitian ini karena model pengembangan ini mempunyai prosedur yang sistematis, sesuai dengan masalah yang melatar belakangi penelitian ini

\section{Uji Efektif}

Efektifitas di ukur dari hasil belajar mahasiswa yang belajar menggunakan Engine TrainerIntegrated Wiring Diagram Aktif. Uji yang diberikan sesuai materi ajar selama penggunaan alat berlangsung. Tes berupa soal soal tes objektif untuk pilihan ganda. Langkah-langkah yang dapat dilakukan dalam menentukan tes adalah membuat kisi-kisi tes, ,menyusun tes, uji coba tes, dan melakukan analisis soal test.

Sebelum digunakan semua instrumen tersebut sudah dilakukan judgement validiti oleh dosen pembimbing sehingga semua instrument tersebut dapat dikatakan layak digunakan dalam penelitian pengembangan Engine Trainer Integrated Wiring Diagram Aktif sebagai Simulator pada pada Mata Kuliah Listrik dan Elektronika Otomotif.
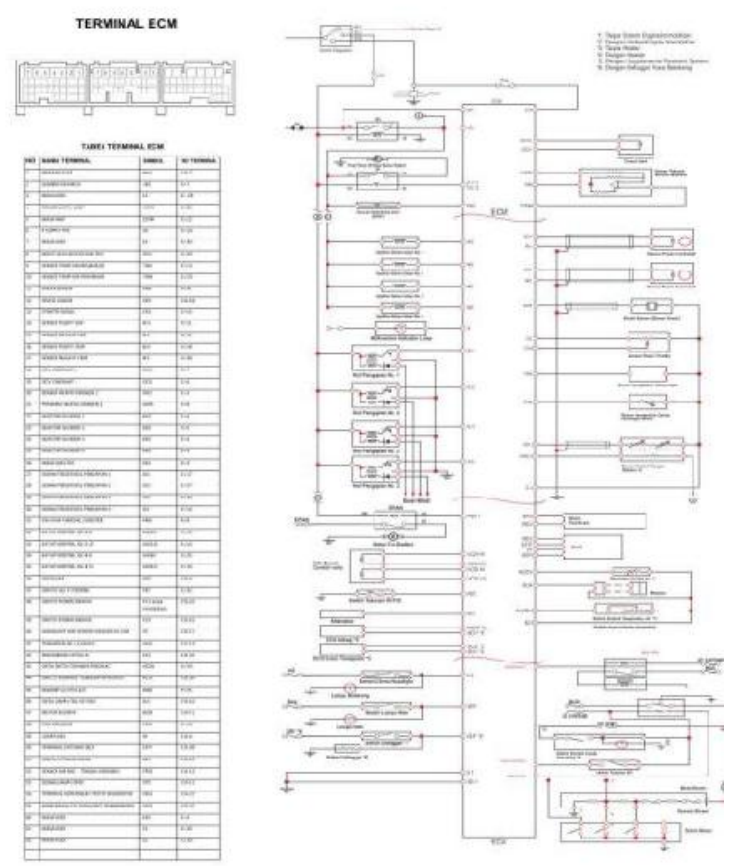

Gambar 2. Wiring Diagram Avanza-xenia (K3VE)

a. Uji validitas instrument

Di dalam suatu soal dikatakan valid jika soal bisa mengukur apa yang akan kita ukur. Pengujian validitas instrumen uji coba dilakukan dengan cara membandingkan antara instrumen dengan materi yang telah diajarkan. Secara teknis dilakukan dengan membuat kisi-kisi instrumen sebagai pedoman dalam memilih butir butir soal tes.

Adapun cara mencari validitas item ini adalah menggunakan $\mathrm{r}$ tabel product moment dengan taraf signifikan 5\%. Apabila $r$ hitung $>r$ tabel maka item soal dinyatakan valid, dan apabila $r$ hitung $<r$ tabel maka item soal tidak valid dan dinyatakan gugur.

Uji validitas instrument rumus product moment sebagai berikut:

$$
\text { rhitung }=\frac{n\left(\sum x y\right)-\left(\sum x\right)\left(\sum y\right.}{\left.\sqrt{\left[\sum x^{2}\right.}-\left(\sum x\right)^{2}\right]\left[n \sum y^{2}-\left(\sum y\right)^{2}\right]}
$$

b. Reliabilitas

Reliabilitas tes berfungsi menunjukkkan apakah suatu tes cukup baik untuk digunakan sebagai alat pengumpul data yang dapat dipercaya. 
Untuk mengukur reliabilitas tes dalam penelitian digunakan rumus Richardson 21 (K -

R.21) di dalam Arikunto (2009: 103) [2] yaitu:

$r H=\left(\frac{n}{n-1}\right)\left(1-\frac{M(n-M)}{n \cdot S t^{2}}\right)$

c. Tingkat kesukaran

Tingkat kesukaran soal menurut Arikunto (2009:207) merupakan bilangan yang menunjukkan sukar dan mudahnya suatu soal [2]. Untuk menentukan tingkat kesukaran soal yang digunakan persamaan:

$$
\mathrm{P} \frac{B}{J_{S}}
$$

d. Daya pembeda (D)

Daya pembeda soal merupakan suatu indikator untuk membedakan antara siswa yang pandai ( berkemampuan tinggi ) dan siswa yang kurang pandai ( berkemampuan rendah). Rumus untuk menghitung daya pembeda adalah

$$
D=\frac{B_{A}}{J_{A}}-\frac{B n}{J_{B}}=P_{A}-P_{B}
$$

2. Analisis Efektivitas Penggunaan Alat Engine Trainer Integrated Wiring Diagram Aktif sebagai Simulator.

Analisis data efektivitas untuk memperoleh data tentang kelayakan produk yang dikembangkan. Teknik pengumpulan data yang digunakan untuk menganalisis data efektifitas adalah melalui tes, karena kemampuan objek yang di ukur pada penelitian ini adalah hasil belajar. Tes terdiri dari dua jenis, yaitu:

a. Pre-test ( tes awal) yaitu tes yang dilakukan sebelum proses belajar ( perlakuan) diberikan. Tes ini dilakukan untuk mengetahui keadaan awal atau pengetahuan awal sampel.

b. Post-test ( tes akhir) yaitu tes yang dilakukan setelah proses pembelajaran ( perlakuan) diberikan. Tes ini diberikan untuk mengukur pengetahuan dan penguasaan sampel setelah menpatkan perlakuan.

Desain tes kemampuan belajar mahasiswa dapat dilihat pada tabel 1

Tabel 1. One Group Pretest- postest design

\begin{tabular}{|c|c|c|}
\hline Pre test & Treatment & Posttest \\
\hline $\mathrm{T} 1$ & $\mathrm{X}$ & $\mathrm{T} 2$ \\
\hline
\end{tabular}

Sumber: Sugiyono (2009:75) [4]

Keterangan:
T1 : Uji awal (pretest) sebelum perlakuan diberikan

T2 : Uji akhir (posttest) setelah perlakuan dilakukan

X : Perlakuan kepada kelompok pembelajaran yang menggunakan alat

Pengujian signifikasi dapat dilakukan dengan melakukan uji Paired Sample T-test. tes ini digunakan untuk mengetahui ada atau tidaknya perbedaan antara dua kelompok sampel yang berpasangan (priyatno, 2009: 98. Syarat pengujian ini adalah apabila data telah diuji normalitas dan homogenitasnya. Pengujian memakai uji dua sisi dengan tingkat signifikansi $a=5 \%$. Pada uji $t$ ini digunakan SPSS versi 22, kriteria pengujian ini adalah seperti pada tabel 2

Tabel 2. Prediket Nilai Akhir Mahasiswa

\begin{tabular}{|l|l|l|l|}
\hline $\begin{array}{c}\text { Nilai } \\
\text { Angka }\end{array}$ & $\begin{array}{c}\text { Nilai } \\
\text { Mutu } \\
\text { (NM) }\end{array}$ & $\begin{array}{c}\text { Angka } \\
\text { Mutu } \\
\text { (AM) }\end{array}$ & \multicolumn{1}{|c|}{$\begin{array}{c}\text { Sebutan Mutu } \\
\text { (SM) }\end{array}$} \\
\hline $85-100$ & A & 4.0 & Dengan Pujian \\
\hline $80-84$ & A- & 3.6 & Sangat Baik Sekali \\
\hline $75-89$ & B + & 3.3 & Baik Sekali \\
\hline $70-74$ & B & 3.0 & Baik \\
\hline $65-69$ & B- & 2.6 & Cukup Baik \\
\hline $60-64$ & C+ & 2.3 & Lebih Dari Cukup \\
\hline $55-59$ & C & 2.0 & Cukup \\
\hline $50-54$ & C- & 1.6 & Kurang Cukup \\
\hline $40-49$ & D & 1.0 & Kurang \\
\hline$\leq 39$ & E & 0.0 & Gagal \\
\hline & T & & Tertunda \\
\hline
\end{tabular}

Sumber : Buku Pedoman Akademik UNP (2014/2015) [5]

\section{Hasil dan Pembahasan}

Data uji validasi diperoleh melalui instrumen validasi yang diisi oleh 3 validator. Validasi produk yang awal dilakukan oleh ahli materi pembelajaran. Tujuan dari validasi ahli materi ialah untuk mengetahui kesesuaian dan ketepatan materi dari produk yang dikembangkan apakah telah sesuai dengan kebutuhan pembelajaran. Lembar validasi berisikan syarat didaktik, syarat konstruksi dan syarat teknis. Yang dilakukan oleh 2 orang dosen teknik otomotif dan 1 orang dosen teknik Mesin FT UNP. (Tabel 3)

Efektifitas penggunaan alat tersebut ditentukan dengan cara melihat pencapaian keberhasilan hasil belajar mahasiswa dengan menggunakan Engine Trainer IntegratedWiring Diagram yang digunakan saat penelitian dan dibandingkan dengan sebelum menggunakan alat Engine TrainerIntegrated Wiring Diagram Aktif. Adapun nilai Akhir (NA) penilaian belajar mahasiswa terdapat pada Tabel 4. 
Tabel 3. Hasil Uji Praktikalitas Oleh Dosen dan teknisi

\begin{tabular}{|c|c|c|c|}
\hline & Item Penilaian & Nilai V & $\begin{array}{c}\text { Keteran } \\
\text { gan }\end{array}$ \\
\hline \multicolumn{4}{|c|}{ Syarat Didaktik } \\
\hline 1. & $\begin{array}{l}\text { Simulator yang } \\
\text { dikembangkan mengacu } \\
\text { pada kurikulum } \\
\text { pendidikan }\end{array}$ & 1,00 & valid \\
\hline 2. & $\begin{array}{l}\text { Simulator yang } \\
\text { dikembangkan dapat } \\
\text { mendukung kegiatan } \\
\text { pemahaman konsep- } \\
\text { konsep yang disampaikan } \\
\text { dalam pembelajaran }\end{array}$ & 0,83 & valid \\
\hline 3. & $\begin{array}{l}\text { Simulator yang } \\
\text { dikembangkan dapat } \\
\text { meningkatkan kualitas } \\
\text { proses pembelajaran yang } \\
\text { efektif }\end{array}$ & 0,83 & valid \\
\hline $\begin{array}{l}4 \\
.\end{array}$ & $\begin{array}{l}\text { Alat yang dikembangkan } \\
\text { dibuat dengan } \\
\text { mempertimbangkan } \\
\text { karakter mahasiswa } \\
\text { sebagai pengguna }\end{array}$ & 1,00 & Valid \\
\hline 5. & $\begin{array}{l}\text { Simulator yang } \\
\text { dikembangkan dapat } \\
\text { menuntun mahasiswa } \\
\text { dalam pembelajaran }\end{array}$ & 0,92 & valid \\
\hline 6. & $\begin{array}{l}\text { Simulator yang } \\
\text { dikembangkan dapat } \\
\text { merangsang minat dan } \\
\text { perhatian mahasiswa }\end{array}$ & 1,00 & valid \\
\hline \multicolumn{2}{|c|}{ Rata-rata } & 0,94 & valid \\
\hline
\end{tabular}

Pengujian signifikansi perbedaan dilakukan dengan menggunakan analisis Paired Sample Ttest dengan memakai program SPSS versi 22 menunjukkan hasil nilai $t$ hitung $<\mathrm{t}$ dan $\mathrm{P}$ value $(0,000<0,05)$. Sebelum dilakukan uji perbandingan terlebih dahulu data harus diuji homogenitas dan normalitasnya. Tabel 5. adalah hasil analisis uji homogenitas menggunakan SPSS.
Tabel 4. Hasil Praktikalitas berdasarkan Respon Mahasiswa

\begin{tabular}{|c|c|c|c|}
\hline$N_{0}$ & Indikator Penilaian & $\%$ & Kategor \\
\hline T. & 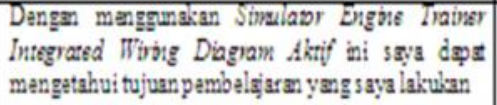 & 93 & $\begin{array}{l}\text { Sangat } \\
\text { Praktis }\end{array}$ \\
\hline 2. & 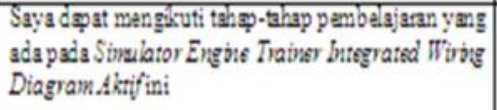 & 92 & $\begin{array}{l}\text { Sangat } \\
\text { Praiktis }\end{array}$ \\
\hline 3. & $\begin{array}{l}\text { Saya dguat dengan mudah mangguna:m Sonulaw } \\
\text { Engine Trainer Integrated Tiving Diagam Aktif }\end{array}$ & 94 & $\begin{array}{l}\text { Sangat } \\
\text { Praktis }\end{array}$ \\
\hline 4. & 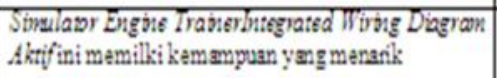 & 84 & Praktis \\
\hline 5. & $\begin{array}{l}\text { Komposisi "Wama Sonulanr Ëgine Trainer } \\
\text { Integrated Tiving DiagramAktif ini sangat menarik }\end{array}$ & $9 !$ & $\begin{array}{l}\text { Sangat } \\
\text { Praktis }\end{array}$ \\
\hline 6. & $\begin{array}{l}\text { Pamodalan yasg disajikan pada Sirulator Eigive } \\
\text { Trainer Inagrated Tiving Diagram Aktí membants } \\
\text { saya dalam memahami mated }\end{array}$ & 86 & $\begin{array}{l}\text { Sangat } \\
\text { Praktis }\end{array}$ \\
\hline 7. & $\begin{array}{l}\text { Saya dapat mengguna:an tools-nols yang aca pada } \\
\text { Sinulapr Engine Trainer Lutegrated Tiving Diggran } \\
\text { Aktif }\end{array}$ & 94 & $\begin{array}{l}\text { Sangat } \\
\text { Praktis }\end{array}$ \\
\hline 8. & 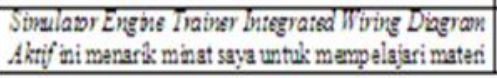 & 84 & Praktis \\
\hline 9. & $\begin{array}{l}\text { Saya tida: membutuhi:an waktu lama untul: } \\
\text { mempelajarimateripembelajaran }\end{array}$ & 92 & $\begin{array}{l}\text { Sangat } \\
\text { Praktis }\end{array}$ \\
\hline 10. & $\begin{array}{l}\text { Sbrulawr Enghe Trainer bitegrated Wbing Dagram } \\
\text { Aktif membantu s aya labih aktif dalam belsjar }\end{array}$ & 80 & Praktis \\
\hline II. & 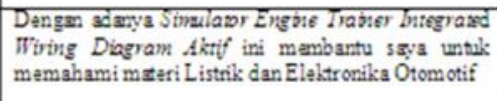 & 90 & $\begin{array}{l}\text { Sangat } \\
\text { Praktis }\end{array}$ \\
\hline 12. & $\begin{array}{l}\text { Sinulaw Enghe Trainer butegrated Tiving Dagran } \\
\text { Aktif ini dapat memfasilitas saya untak belaja } \\
\text { mandiri }\end{array}$ & 92 & $\begin{array}{l}\text { Sangat } \\
\text { Praktis }\end{array}$ \\
\hline 13 & $\begin{array}{l}\text { Saya tida: butuh wakta yag lama until: mempelajan } \\
\text { Kalistrikan EI dengan bantuan media pembelajarm } \\
\text { ini }\end{array}$ & 87 & $\begin{array}{l}\text { Sangat } \\
\text { Praktis }\end{array}$ \\
\hline 14 & Media ini membuat saya lebth altif dalsm belajar. & 84 & Praktis \\
\hline 15 & $\begin{array}{l}\text { Media ini membants saya mempemudah untak } \\
\text { memahami materikelistriksn } E F I\end{array}$ & 92 & $\begin{array}{l}\text { Sangat } \\
\text { Praktis }\end{array}$ \\
\hline 16 & $\begin{array}{l}\text { Media ni dæast memiasilitasi says untuk belaja } \\
\text { mandiri }\end{array}$ & 90 & $\begin{array}{l}\text { Sangat } \\
\text { Praktis }\end{array}$ \\
\hline 17 & Bahass yang digunakan modia ini mudah dimengenti & 88 & Praktis \\
\hline$\overline{18}$ & Informasiyangada diam mediajelas & $\overline{84}$ & $\overline{\text { Praktis }}$ \\
\hline 19 & Sudah baguskah pengembangan media ini & 93 & $\begin{array}{l}\text { Sangat } \\
\text { Praktis }\end{array}$ \\
\hline 20 & Apalah anda satujudengan madia baru int & 93 & $\begin{array}{l}\text { Sangat } \\
\text { Praktis }\end{array}$ \\
\hline & Total & 89 & $\begin{array}{l}\text { Sangat } \\
\text { Praktis }\end{array}$ \\
\hline
\end{tabular}


Tabel 5. Uji Homogenitas

\begin{tabular}{|c|c|c|c|}
\hline $\begin{array}{c}\text { Levene } \\
\text { Statistic }\end{array}$ & df1 & df2 & Sig \\
\hline 2,486 & 1 & 16 &, 085 \\
\hline
\end{tabular}

\begin{tabular}{|c|r|r|r|r|r|}
\hline & $\begin{array}{c}\text { Sum of } \\
\text { Square }\end{array}$ & df & Mean Square & F & Sig \\
\hline $\begin{array}{c}\text { Between } \\
\text { Group } \\
\begin{array}{c}\text { Within } \\
\text { Group } \\
\text { Total }\end{array}\end{array}$ & 1005,967 & 13 & 77,382 & 1,230 &, 343 \\
\hline
\end{tabular}

1. Apabila nilai signifikasi $<0,05$ bisa dikatakan bahwa varian dari dua atau lebih kelompok populasi data adalah tidak menyerupai

2. Apabila nilai signifikasi $>0,05$ bisa dikatakan bahwa varian dari dua atau lebih kelompok populasi data adalah menyerupai

Berdasarkan output spss diatas diketahui bahwa nilai signifikasi variabel postest berdasarkan variabel pretest $=0,085>0,05$, artinya data variabel postest berdasarkan variabel pretest mempunyai variant yang sama atau homogen.

\section{KeSIMPULAN}

Berdasarkan hasil penelitian pengembangan Simulator Engine Trainer Integratedwiring diagram aktif yang telah dilakukan, maka diperoleh kesimpulan sebagai berikut:

Menganalisa mahasiswa dan menganalisa konsep yang mendukung penerapan Simulator yang akan dikembangkan. Kemudian setelah itu melakukan perancangan Simulator yang mengacu kepada komponen media pembelajaran yaitu syarat didaktik, syarat konstruksi, dan syarat teknis. Hasil dari media yang dikembangkan pada penelitian ini adalah Simulator Engine Trainer IntegratedWiring Diagram Aktif yang dapat digunakan sebagai media pembelajaran pada mata kuliah Listrik dan Elektronika Otomotif.

Hasil pengujian validitas yang mengacu pada tiga aspek komponen media berada pada kondisi valid. Kepraktisan Simulator Engine Trainer Integrated Wiring Diagram aktif dilihat dari respon praktisi yaitu dosen dan mahasiswa. Dalam pembelajaran dapat dilihat dari keterlaksanaan penggunaan simulator Engine Trainer Integrated Wiring Diagram Aktif sebagai media pembelajaran dapat digunakan dengan baik. Simulator yang dikembangkan efektif untuk meningkatkan hasil belajar mahasiswa.

\section{DAfTar Pustaka}

[1] Putra, D. S., Fernandez, D., \& Aprilindo, Y. (2016). PERANCANGAN PERAGA SENSOR KETUKAN UNTUK MEDIA PEMBELAJARAN. VANOS Journal of Mechanical Engineering Education, 1(2).

[2] Arikunto, Suharsimi. Prosedur Penelitian: Jakarta: Rineka Cipta (2009)

[3] Sanjaya, Wina. Strategi Pembelajaran Berorientasi Standar Proses Pendidikan, Jakata: Pranada Media Group (2003)

[4] Sugiyono. Metode Penelitian Kuatitatif, Kualitatif, dan R\&D. Bandung: Alfabeta (2013)

[5] Ganefri, dkk, Buku Pedoman Akademik Universitas Negeri Padang 2014/2015, Fakultas Teknik Buku Pedoman Penyusunan Tesis dan Disertasi Program Pasca Sarjana Fakultas Teknik Universitas Negeri Padang (2014)

\section{Biodata Penulis}

Rifdarmon, Lahir di Tanjung Jati, 11 September 1977, menyelesaikan (S1) pada Jurusan Pendidikan Teknik Otomotif FT UNP Padang Tahun 2004 dan pendidikan pasca sarjana (S2) Pendidikan Teknologi Kejuruan pada tahun 2018. Sejak tahun 2006 menjadistaf pengajar dijurusan Teknik Otomotif Fakultas Teknik Universitas Negeri Padang. 
